\title{
PSA 2020-2021 Study Capacity Report
}

Bastien Paris, Hans Rocha IJzerman, and Patrick S. Forscher

$\begin{array}{ll}\text { Introduction } & 3\end{array}$

Overview of the Psychological Science Accelerator 4

Evolution of our member pool over time $\quad 5$

Technical notes 5

Status of all on-going PSA studies (except for PSA_007) 6

$\begin{array}{ll}\text { Technical notes } & 6\end{array}$

$\begin{array}{ll}\text { Data Collection Capacity } & 7\end{array}$

Estimation of our general data collection capacity $\quad 8$

$\begin{array}{lc}\text { Technical notes } & 8\end{array}$

Variations of our data collection capacity across important PSA member characteristics 10

$\begin{array}{ll}\text { Technical notes } & 11\end{array}$

$\begin{array}{ll}\text { Administrative Capacity } & 12\end{array}$

$\begin{array}{ll}\text { Overview of our current administrative roster } & 13\end{array}$

$\begin{array}{ll}\text { Technical notes } & 13\end{array}$

$\begin{array}{ll}\text { World regions of our administrative roster } & 14\end{array}$

$\begin{array}{ll}\text { Estimation of our administrative capacity } & 16\end{array}$

$\begin{array}{ll}\text { Technical notes } & 16\end{array}$

Variations of our administrative capacity (for each of the different PSA role) across $\begin{array}{ll}\text { important members characteristics } & 17\end{array}$

$\begin{array}{ll}\text { Data Manager } & 17\end{array}$

$\begin{array}{ll}\text { Ethics coordinator } & 18\end{array}$

$\begin{array}{ll}\text { Methodologist } & 19\end{array}$

$\begin{array}{ll}\text { Project monitor } & 20\end{array}$

$\begin{array}{ll}\text { Translation coordinator } & 21\end{array}$

$\begin{array}{ll}\text { Technical notes (these apply for each PSA role) } & 21\end{array}$

Matched / Unmatched Requirements (+ Suggestions) 23

Data Collection Capacity 23 
$\begin{array}{ll}\text { Administrative Capacity } & 24\end{array}$

$\begin{array}{lr}\text { Broad suggestions / Comments } & 25\end{array}$

Regarding the way we ask profile information $\quad 25$

Defining inclusion and diversity criteria, and assessing whether they are fulfilled $\quad 26$

Information that we should make easier to obtain 26

$\begin{array}{ll}\text { Poll our members to retrieve more accurate data } & 27\end{array}$

$\begin{array}{ll}\text { Formalizing the writing process of these reports } & 27\end{array}$

$\begin{array}{ll}\text { From a time perspective } & 27\end{array}$

$\begin{array}{ll}\text { Defining a roadmap } & 27\end{array}$

Keeping track of data that concern our administrative team 27

$\begin{array}{ll}\text { Characteristics Choices } & 29\end{array}$

Member information not reported $\quad 29$

Member information reported $\quad 29$ 


\section{Introduction}

This document estimates the Psychological Science Accelerator's study capacity for the 20202021 academic year. As described in our Study Capacity Policy, study capacity is determined by the PSA's data collection capacity, or the amount and kind of participant data the PSA can collect in a given year, and its administrative capacity, or its ability to perform the administrative tasks required to collect participant data.

To estimate the PSA's data collection and administrative capacities, we draw on the PSA member website and the various spreadsheets and documents that track the status of the PSA's ongoing projects. The PSA's leadership should use this report to determine the number and kind of studies that the PSA can take on during the upcoming academic year.

Many parts of this report are also relevant to helping the PSA live up to its founding principle of diversity and inclusion. However, the primary goal of this report is to meet the reporting requirements laid out in the capacity policy.

\section{Here are five big-picture takeaways on the PSA's study capacity for 2020-2021:}

- The PSA currently has $1400+$ members from 71 countries

- Out of seven studies, six are still underway collecting data

- Based on our past data collection capacity, we have the ability to recruit a minimum of 20,000 participants over the upcoming scholarly year for new PSA projects

- Two out of three PSA members come from so-called "WEIRD" countries (defined in this report as North America and Western Europe)

- We do not have sufficient information to accurately estimate the number of administrative hours available for each PSA role

The remainder of this report consists of four broad sections. The first subsection details the current status of the PSA and its projects. The next two sections estimate the PSA's data collection and administrative capacities, respectively, along with the subcomponents that make up these capacities.

The final section lists the requirements for study capacity reporting that are laid out in the PSA's Study Capacity Policy. Although we were able to meet many of these requirements in the process of compiling this report, we were not able to meet all of them. This final section therefore gives a series of recommendations for how we can better meet these reporting requirements in future years.

Throughout this report, we provide technical notes about how we derived each estimate at the end of each section and subsection.

\section{Overall technical notes about this report:}

- All the information on the basis of which we wrote these reports were retrieved on October 1, 2020.

- Analysis and Visualizations were performed with Python 3.6.8 and the Plotly library.

- The data and scripts necessary to compile this report are deposited at https://osf.io/r6fg2/ 


\section{Overview of the Psychological Science Accelerator}

This section provides a big-picture overview of the current status of the PSA as of October 2020 by examining its membership and how this membership has evolved throughout the academic year. This section also examines the current status of the PSA's ongoing studies.

Here are the big-picture takeaways from this subsection:

- The PSA currently has $1400+$ members from 71 countries

- Out of seven studies, six are still actively collecting data

- Based on the recruitment goals for the PSA's ongoing studies and excluding PSA_007, the PSA will need to recruit 30,000 participants in order to complete its active roster of projects 


\section{Evolution of our member pool over time}

Figure 1. Evolution of our member pool over time

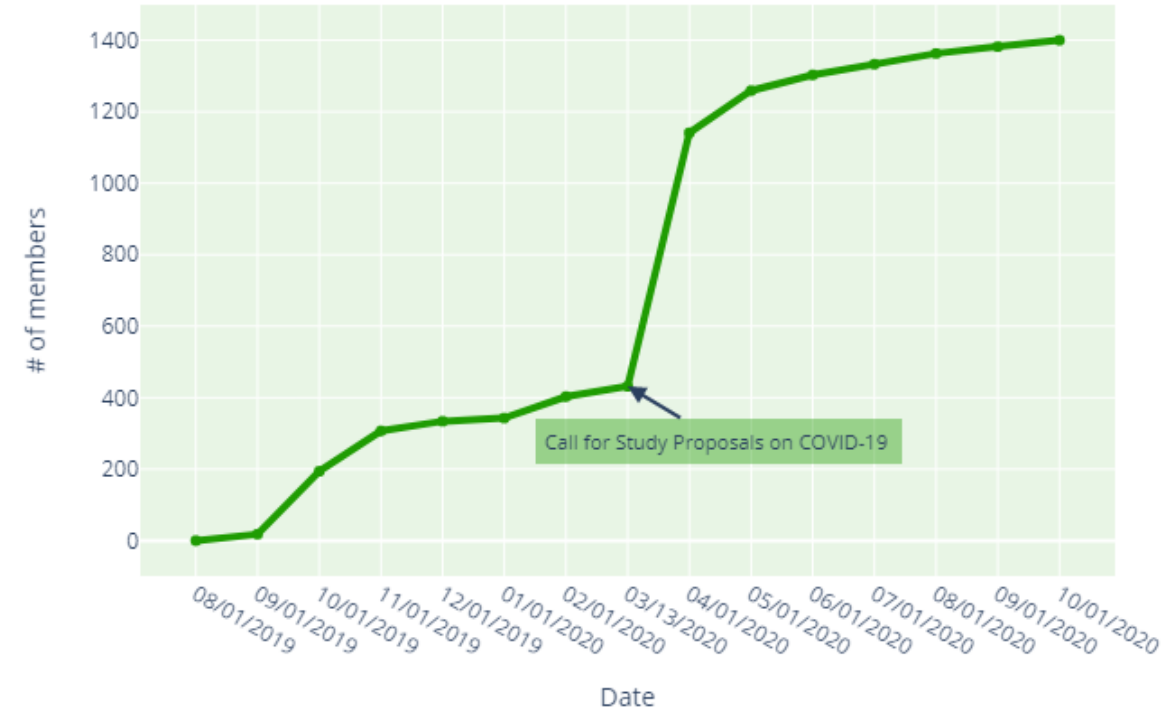

Our network is currently composed of 1400+ members from 71 countries (for other characteristics on our members, see Variations of our data collection capacity across important PSA member characteristics). The PSA's membership roster saw especially impressive growth following the announcement of the PSACR suite of studies.

\section{Technical notes}

- This timeline was created with the timestamp associated with the registration of each of our members. 
Status of all on-going PSA studies (except for PSA_007)

Table 1. Status of all on-going PSA studies (except for PSA_007)

\begin{tabular}{|c|c|c|c|c|c|}
\hline PSA Study & $\begin{array}{c}\text { Count of collected } \\
\text { usable data }\end{array}$ & Targeted count & $\begin{array}{c}\text { Bundled for data } \\
\text { collection? }\end{array}$ & $\begin{array}{c}\text { Complered data } \\
\text { collection }\end{array}$ & Terminated \\
\hline PSA_001 & 11570 & 9000 & No & Yes & No \\
\hline PSA_002 & 2317 & 3880 & PSA_002/3 & No (60\% completed) & No \\
\hline PSA_003 & 2317 & 3880 & PSA_002/3 & No (60\% completed) & No \\
\hline PSA_004 & 2491 & 3250 & No & No (77\% completed) & No \\
\hline PSA_005 & 0 & 2700 & No & No (0\% completed) & No \\
\hline PSA_006 & 4403 & 18637 & No & No (24\% completed) & No \\
\hline PSA_CR & 42792 & 59447 & No & No (72\% completed) & N \\
\hline
\end{tabular}

Estimated count of data left to collect for ongoing PSA projects: 35911

Table 1 gives a broad view of the current status of the current roster of PSA projects. We can use the information in this table to get a big-picture sense of how much data collection and administrative capacity these studies currently take up. This is because these studies represent ongoing commitments for the PSA to collect data (to help these studies meet their recruitment goals) and administer (to ensure that the administrative tasks required to complete a study are actually accomplished.

The "estimated count of data left to collect for ongoing PSA projects" (displayed in the bottom right of the table) constitute a quantity of data our different members committed to collect.

\section{Technical notes}

- Displayed information was retrieved from (1) the preprint/OSF page of the relevant PSA project, and (2) the data collection tracker of the relevant PSA project.

- "Count of collected usable data" refers to the amount of data that is usable for the data analysis. When not specified, we considered that the amount of data reported was the amount of usable data.

- If two studies were bundled together for data collection, "Estimated count of data left to collect for ongoing PSA projects" (displayed on the bottom right of the table) was incremented only with the biggest number of data left to collect between the two studies.

- We didn't take into account the studies that got accepted but haven't started yet (here, PSA_007). 


\section{Data Collection Capacity}

This section (1) provides an estimation of our data collection capacity, and (2) details how data collection capacity varies across important members characteristics.

Here are the big-picture takeaways from this section:

- Based on our past data collection capacity, we have the ability to recruit at least 20,000 participants over the upcoming academic year for new PSA projects

- Future data collection capacity will be affected by natural growth in membership, study announcements, what types of data we collect, and unforeseen events like Covid-19. The precise effects of these factors are difficult to project

- Two out of three PSA members come from so-called "WEIRD" countries (defined in this report as North America and Western Europe)

- The most highly represented specialty in our network is social psychology $(\simeq 20 \%)$ 
1) Estimation of our general data collection capacity

Table 2. Data collection state of all ongoing PSA projects (with the exception of PSA_007)

\begin{tabular}{|c|c|c|c|c|c|}
\hline PSA Study & First data collected & Last data collected & $\begin{array}{l}\text { Count of collected } \\
\text { usable data }\end{array}$ & $\begin{array}{l}\text { Estimated count of } \\
\text { collected data (from } \\
\text { 09/01/2019 to 08/01/2020) }\end{array}$ & $\begin{array}{l}\text { Bundled for data } \\
\text { collection? }\end{array}$ \\
\hline PSA_001 & NaT & nan & 11570 & 0 & No \\
\hline PSA_002 & $09 / 03 / 2019$ & $03 / 16 / 2020$ & 2317 & 2317 & PSA_002/3 \\
\hline PSA_003 & $09 / 03 / 2019$ & $03 / 16 / 2020$ & 2317 & 2317 & PSA_002/3 \\
\hline PSA_004 & $08 / 27 / 2019$ & ongoing & 2491 & 1958 & No \\
\hline PSA_005 & NaT & nan & 0 & 2461 & No \\
\hline PSA_006 & $04 / 14 / 2020$ & ongoing & 4403 & 8146 & PSA_CR001/3 \\
\hline PSA_CR001 & $05 / 06 / 2020$ & ongoing & 16200 & 4595 & No \\
\hline PSA_CR002 & $05 / 06 / 2020$ & ongoing & 9138 & 9383 & PSA_CR001/3 \\
\hline PSA_CR003 & $04 / 23 / 2020$ & ongoing & 17454 & & 0 \\
\hline
\end{tabular}

Estimated count of unique collected data (from 09/01/2019 to 08/01/2020): 23432

Table 2 gives a broad overview of the PSA's ability to recruit participants for the current academic year. In the bottom right, we estimate the count of unique data we collected during the previous academic year (from 09/01/2019 to 08/01/2020). We suspect that our capacity to recruit general participants (i.e., participants without any particular special characteristics) should be close to this number.

Our data collection capacity is partly a function of the number of PSA members. The number of PSA members saw spectacular growth in the past academic year due in large part to the launch of the PSACR suite of studies. It is unclear whether the PSA will see similar growth over the coming academic year.

These estimates do not take into account disruptions due to the Covid-19 pandemic. Covid-19 has forced many of the current roster of studies to move to online data collection, which is faster than in-person collection but which also offers less flexibility in terms of the experimental tasks that are delivered to participants.

In addition, these estimates do not take into account the fact that certain types of data collection are easier in some world regions than others -- for example, data collection in Kenya may require the hiring of field workers to deliver questionnaires in person.

\section{Technical notes}

- Displayed information was retrieved from the data collection tracker of each project. The data collection tracker usually consists of a Google Sheet or Shiny app

- "Count of collected usable data" refers to the amount of data that is usable for the data analysis. When not specified, we assumed that the amount of data reported in the project tracker is the amount of usable data 
- "Estimated count of collected data (from 09/01/2019 to 08/01/2020)" was calculated as follows:

- We computed the number of days that separated the date where the first data was collected from the date where the last data was collected. If the second date wasn't available, we assumed that the last data was collected the day where we retrieved the count of usable data (10/01/2020)

- We divided the count of collected usable data by the variable calculated above. This returned the mean number of usable data collected per day

- Finally, we computed "Estimated count of collected data (from 09/01/2019 to 08/01/2020)" by multiplying this number by the number of days data collection was performed during the time period of interest (from 09/01/2019 to 08/01/2020)

- The number at the bottom right is the sum of this variable for each study. If two studies were bundled together for data collection, this number was incremented only with the biggest number of usable data collected between the two studies 


\section{1) Variations of our data collection capacity across important PSA member characteristics}

Figure 2. Number of members across age, gender, world region, academic position, and macro specialty.
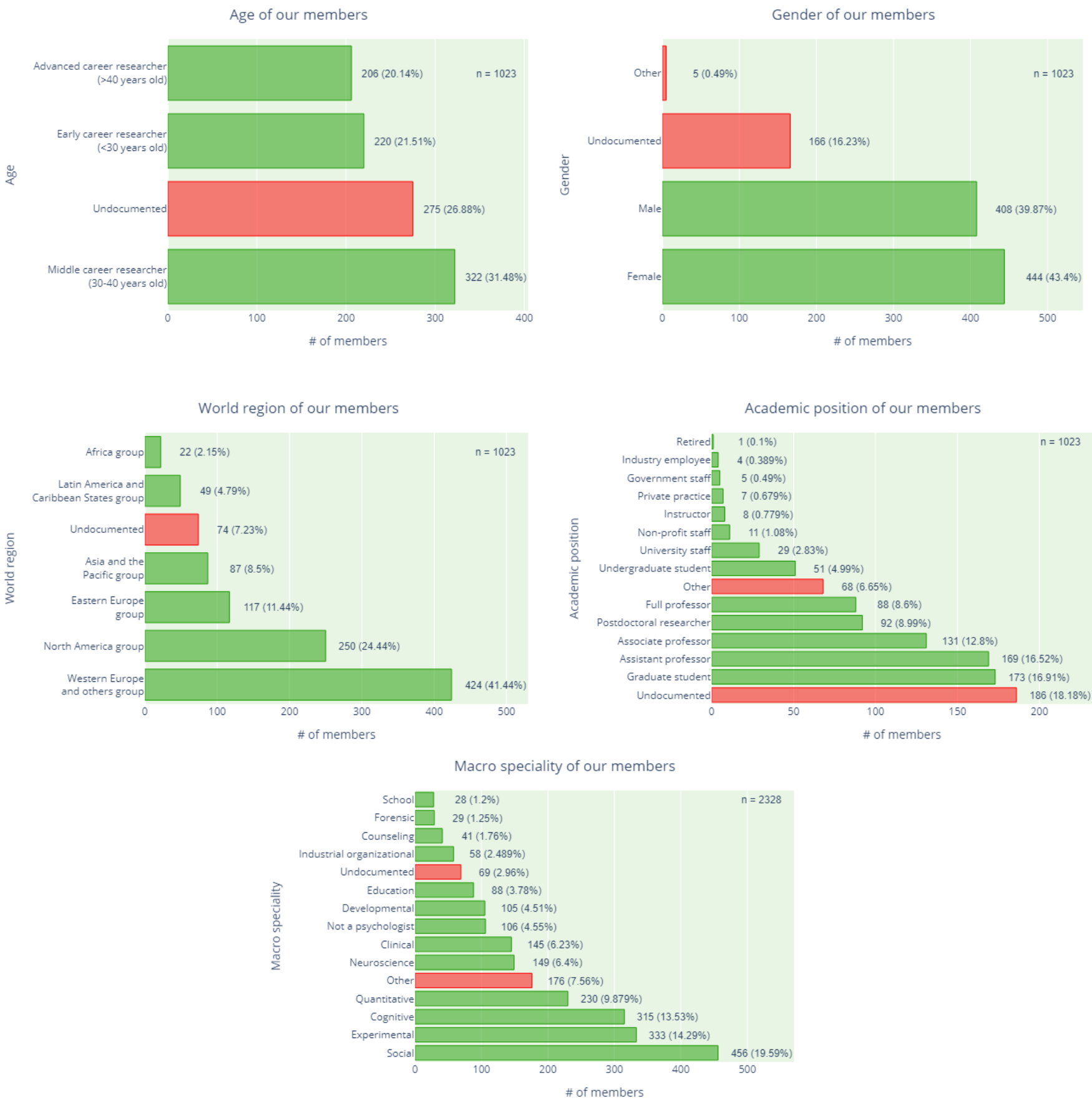

The above five figures above show how general data collection varies across important member characteristics (see Characteristics choices for our underlying reasoning).

If we presume that our members will equally participate in data collection processes within the upcoming academic year, most of the data we'll collect will come from Western Europe 
(categorized into a "Western European and others group", consisting of $41 \%$ of the membership) and Canada/the USA (categorized into a "North America group", consisting of $24 \%$ of the membership). That would mean that about 2 out of 3 participants in our studies could potentially come from these WEIRD countries.

Our network consists of members specialized in all the different field areas we defined, but Social Psychology is the most highly represented field (20\% of the membership).

\section{Technical notes}

- Specific answers

-Undocumented means that the member didn't fill this field in their member profile

- Other consists of a category of various categories that by themselves did not have a sufficient number to create its own category.

\section{- Categories}

- World regions ${ }^{1}$ : We've created different clusters on the basis of the United Nations Regional Groups (see https://en.wikipedia.org/wiki/United Nations Regional Groups ). We deviated slightly from the distinction by creating an additional cluster for Canada and the USA (North America group).

- Age: We've arbitrarily created three different clusters ( $<30$ years old, 30-40 years old, $>40$ years old) which we somewhat arbitrarily named "early career researcher", "middle career researcher", and "advanced career researcher. Though exceptions to these cases may exist, they probably most accurately reflect members' career stages.

- Academic position: Here, we report all the different positions one can tick in the profile section.

- Macro specialty: Here, we report all the different research areas one can tick in the profile section.

\footnotetext{
${ }^{1}$ For the "Western Europe and others group", "others" includes Australia, Israel, New Zealand, and Turkey.
} 


\section{Administrative Capacity}

This section provides an estimation of our administrative capacity, and how it varies across important members characteristics.

\section{Here are the big-picture takeaways from this section:}

- There is a general interest of our members in contributing to different PSA administrative roles

- We do not have sufficient information to accurately estimate the number of administrative hours available for each PSA role

- Interest in PSA administrative roles varies by member characteristics. In particular, most of the people interested in administration are from WEIRD countries. The one exception is interest in translation ( $41 \%$ non-WEIRD) 


\section{1) Overview of our current administrative roster}

Table 3. Count of people involved in PSA Administrative roles

\begin{tabular}{|c|c|}
\hline Administrative role & Number \\
\hline Director & 1 \\
\hline Associate Director & 5 \\
\hline Committee (Assistant Director) & 13 \\
\hline Committee (Member) & 31 \\
\hline Proposing Authors (accepted projects) & 16 \\
\hline Study Personnel & 49 \\
\hline Total & 115 \\
\hline
\end{tabular}

Count of unique people involved in PSA Administrative role(s): 77

\section{Technical notes}

- Data were retrieved from https://psysciacc.org/about/people/ and the different PSA studies pages. 
2) World regions of our administrative roster

Figure 3. World regions of our administrative roster for each administrative role

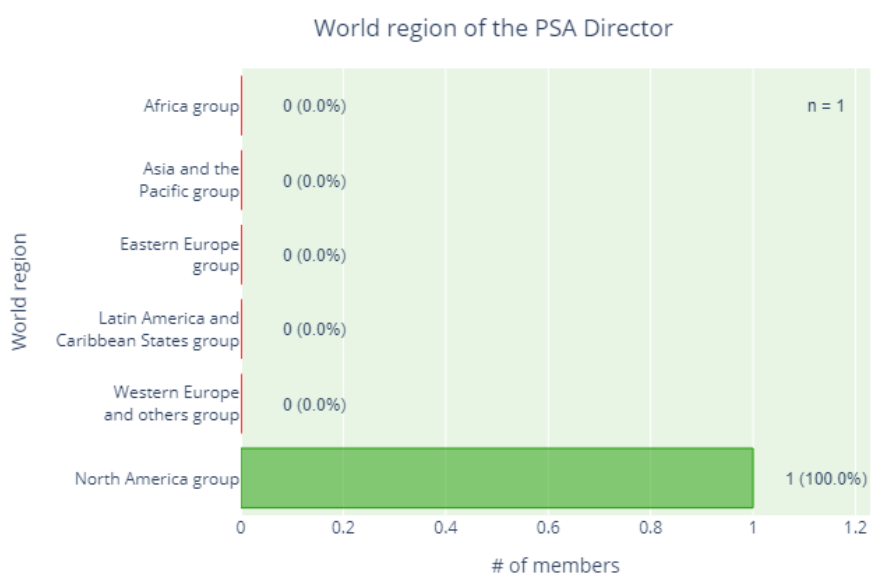

World region of the PSA Committee (Assistant Directors)

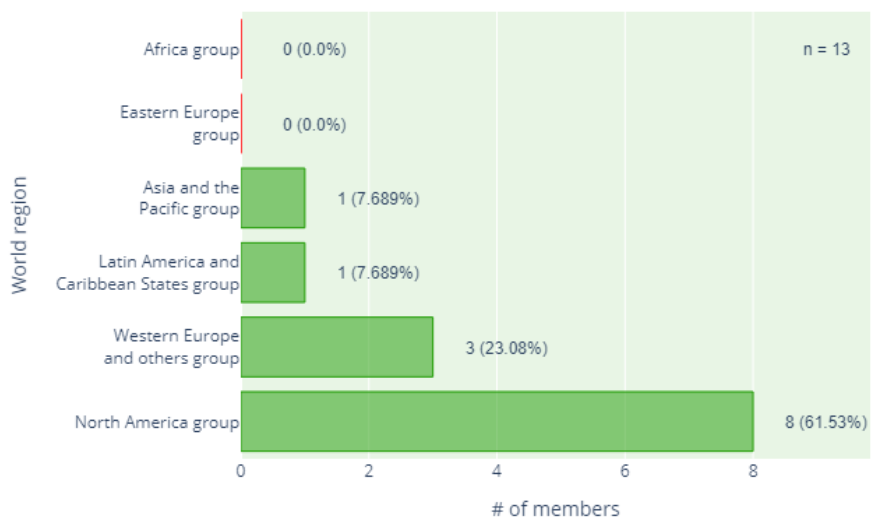

World region of the PSA Proposing Authors of accepted projects

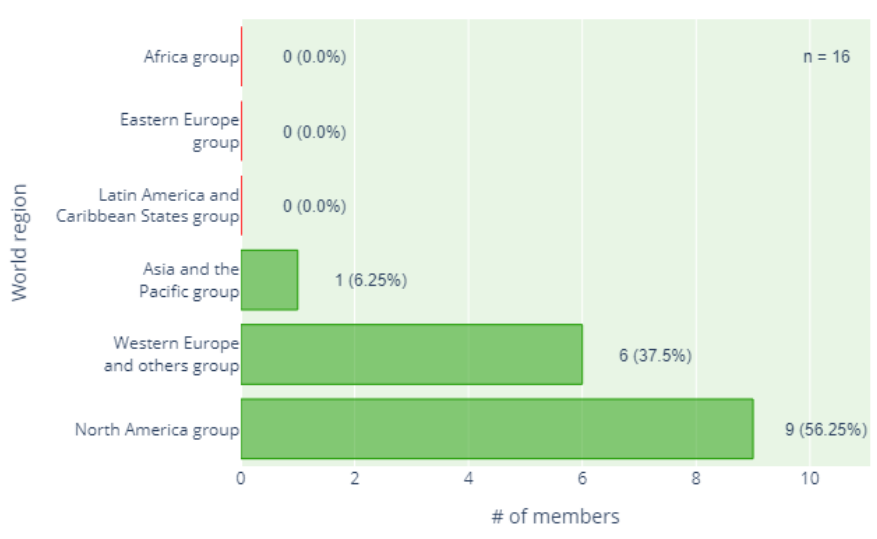

World region of the PSA Associate Directors

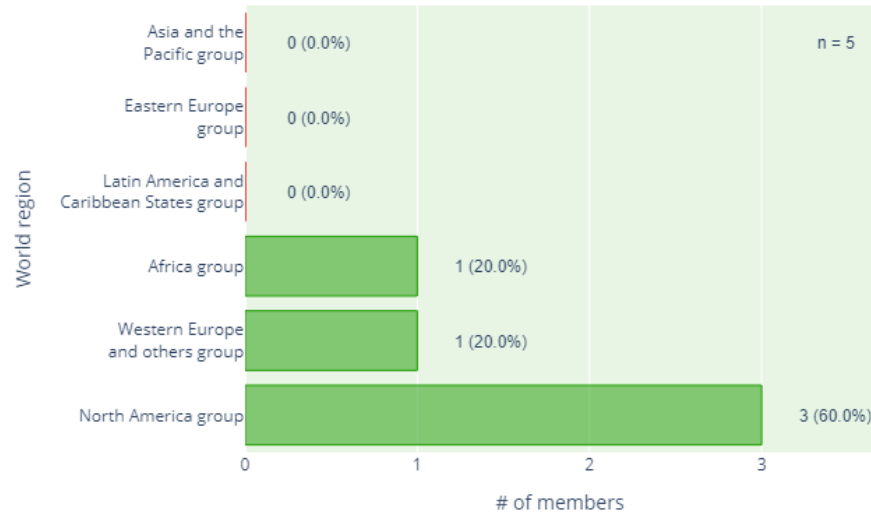

World region of the PSA Committee (Members)

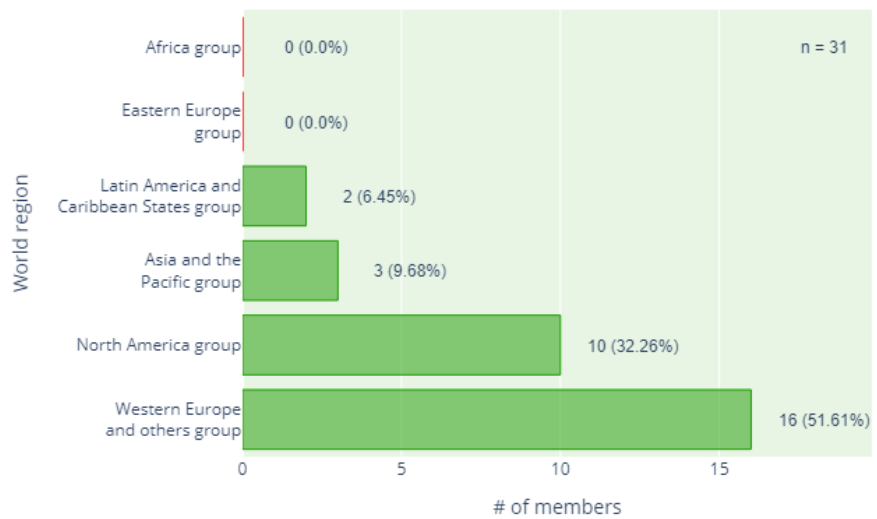

World region of the PSA Study Personnel

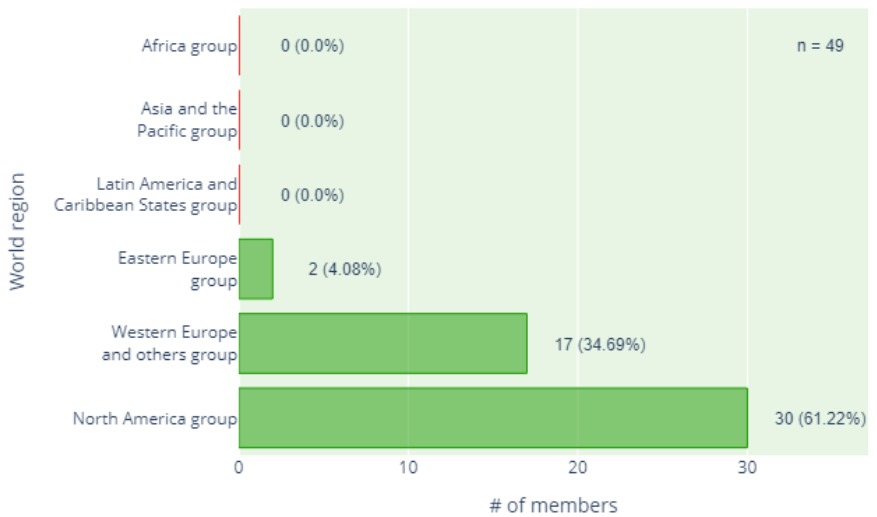

Figure 4. World regions of unique people involved in all of the PSA's Administrative role(s) 


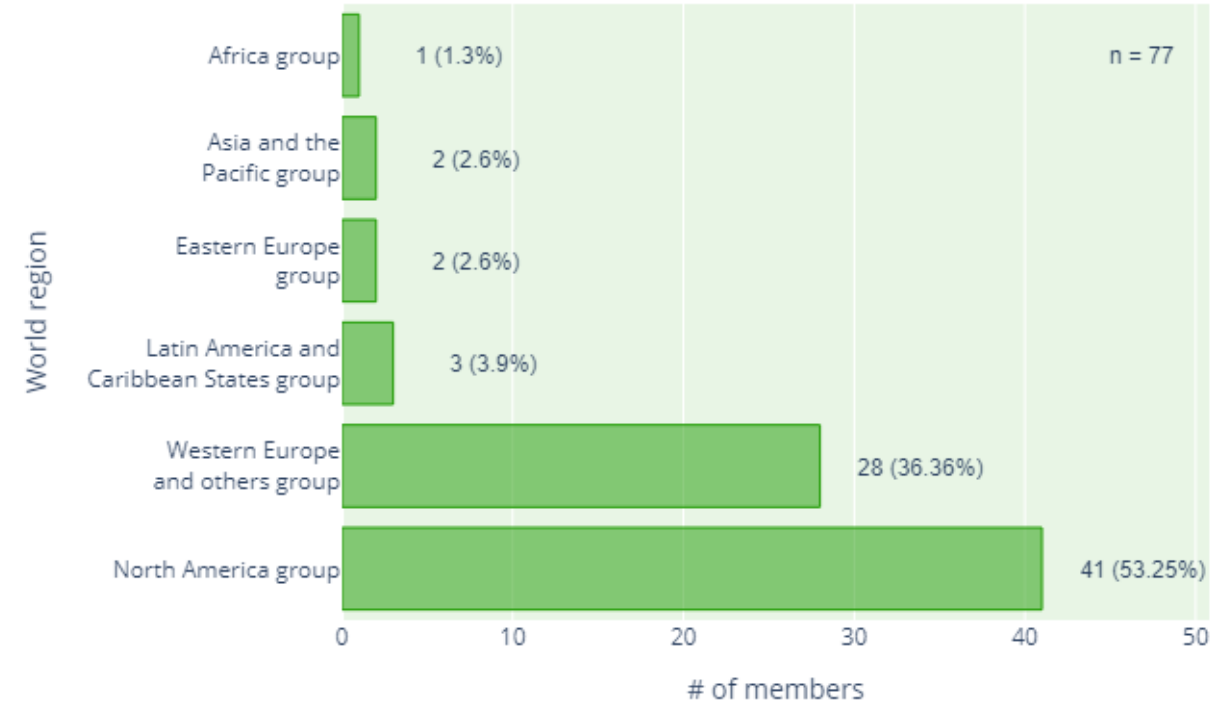

\section{Technical notes}

- The World region of each administrative staff was retrieved through Google searches 


\section{3) Estimation of our administrative capacity}

Figure 5. Number of members interested in different PSA administrative roles

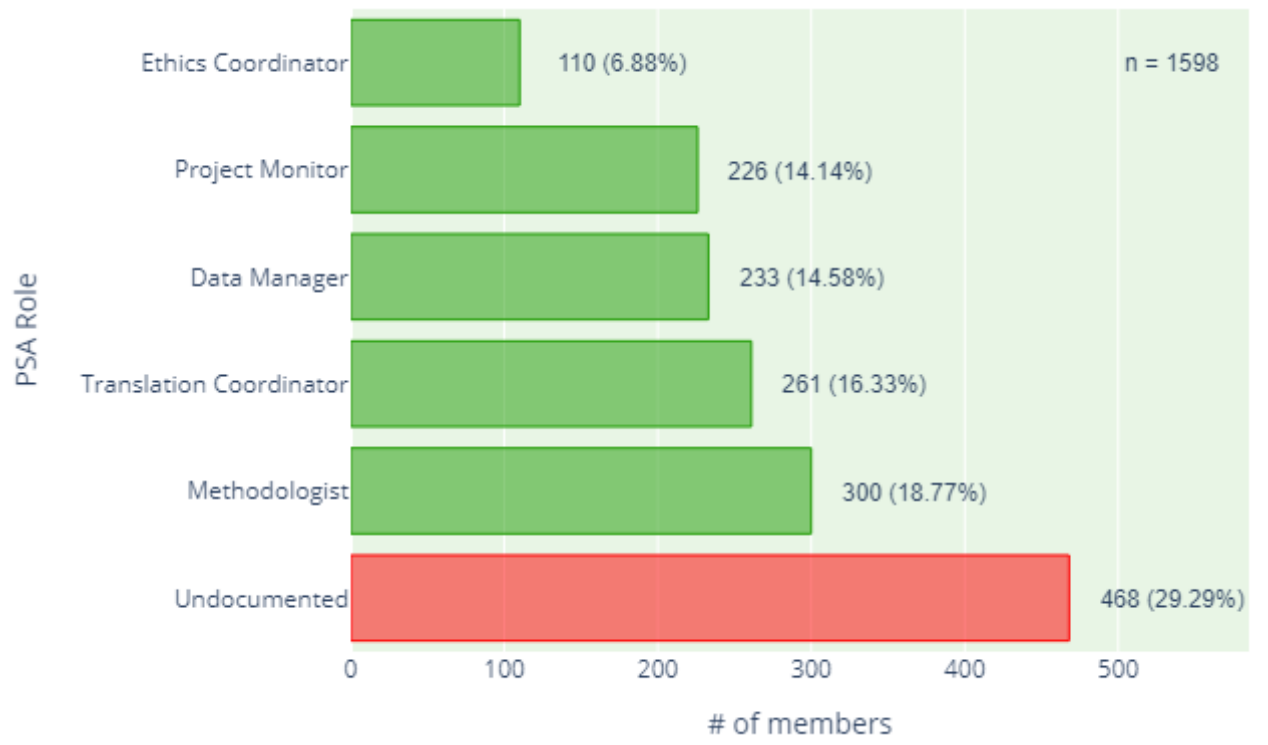

Our member website asks whether members are interested in different PSA administrative roles. Figure 5 displays the number of people who express this interest broken down by role. However, this information is not easily translatable into an estimate of administrative capacity. Although many members express interest in administration in the abstract, calls for project monitors, data managers, and methodologists are seldom met with a strong response from members.

We discuss solutions to the problem of estimating administrative capacity in Matched / $\underline{\text { Unmatched Requirements (+ Suggestions) and Broad suggestions / Comments. }}$

\section{Technical notes}

- Total number of data (displayed in the upper right of the figure) is higher than our total number of members. The reason behind is that members can show interest toward multiple roles. 


\section{4) Variations of our administrative capacity (for each of the different PSA role) across important members characteristics}

\section{a) Data Manager}

Figure 6. Number of members interested in the "Data Manager" role across age, gender, world region, academic position, and macro specialty.
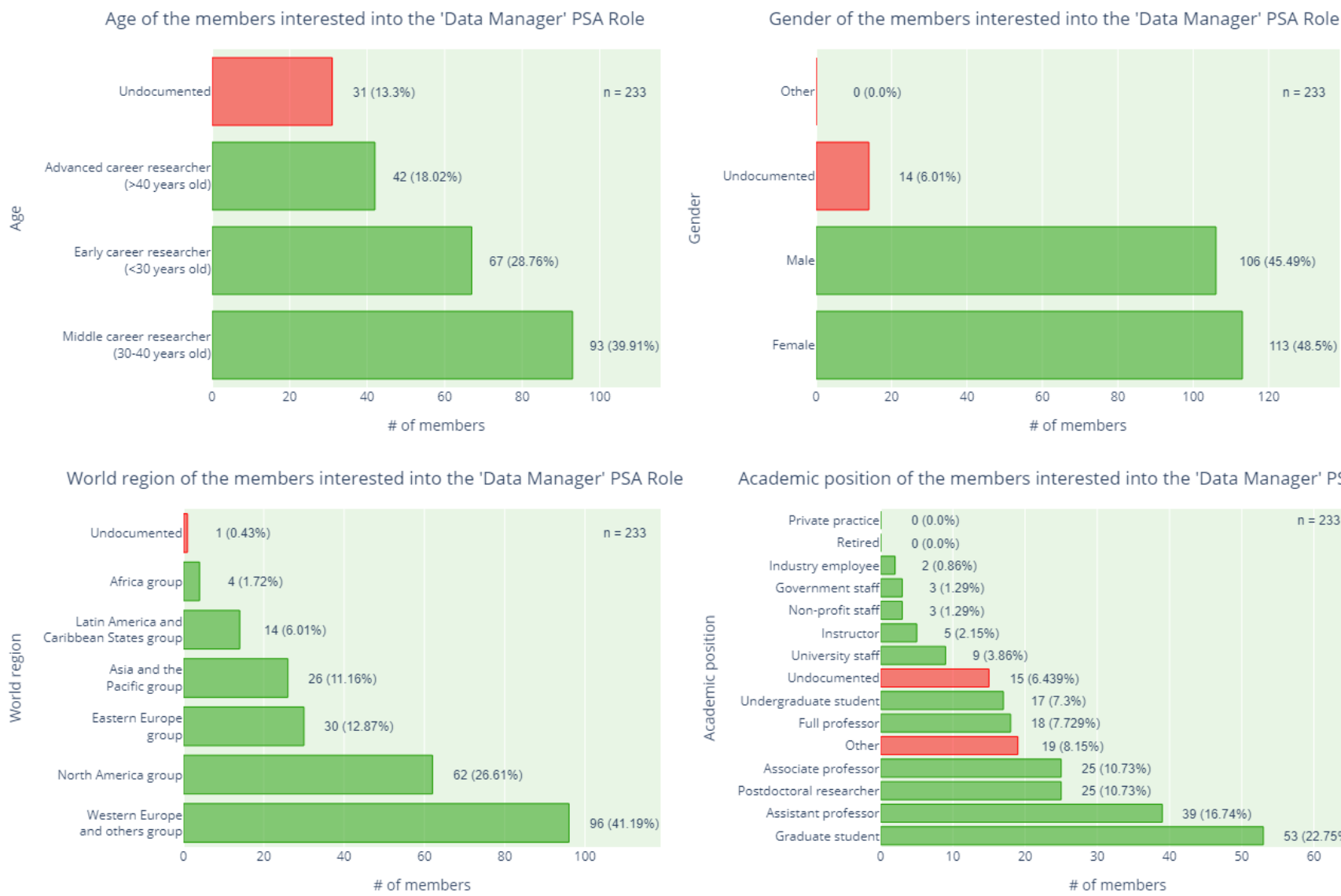

Academic position of the members interested into the 'Data Manager' PSA Role

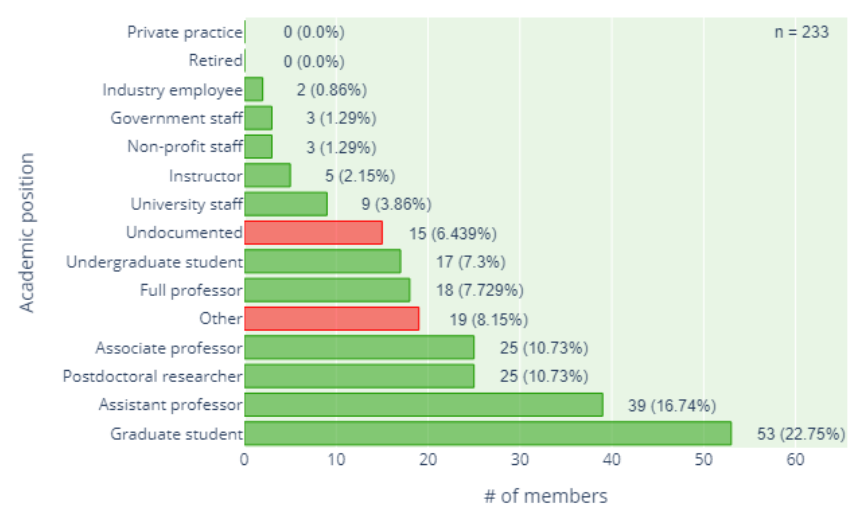

Macro speciality of the members interested into the 'Data Manager' PSA Role

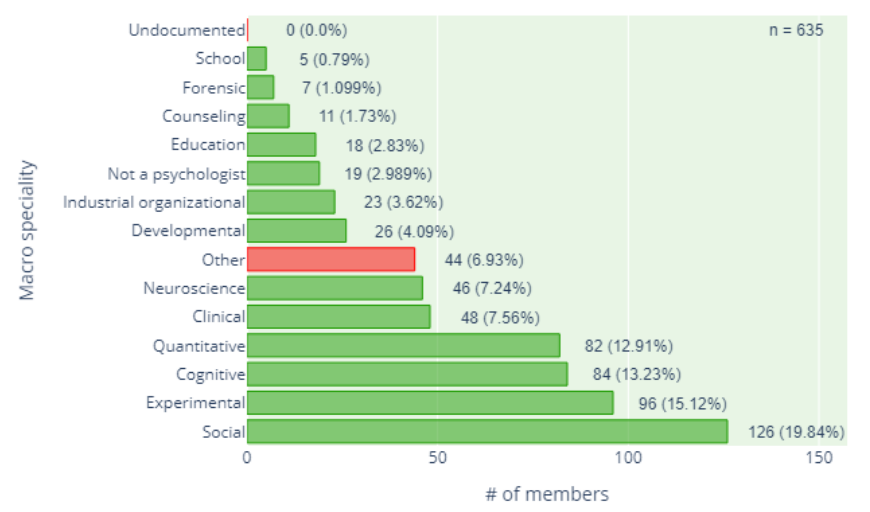

These five figures show the breakdown of interest in the "Data Manager" role across important member characteristics (see Characteristics choices for our underlying reasoning). Most (78\%) of the people interested in this position are from WEIRD countries.

Similar analyses of the other five administrative roles are displayed below. 


\section{b) Ethics coordinator}

Figure 7. Number of members interested in the "Ethics Coordinator" role across age, gender, world region, academic position, and macro specialty.
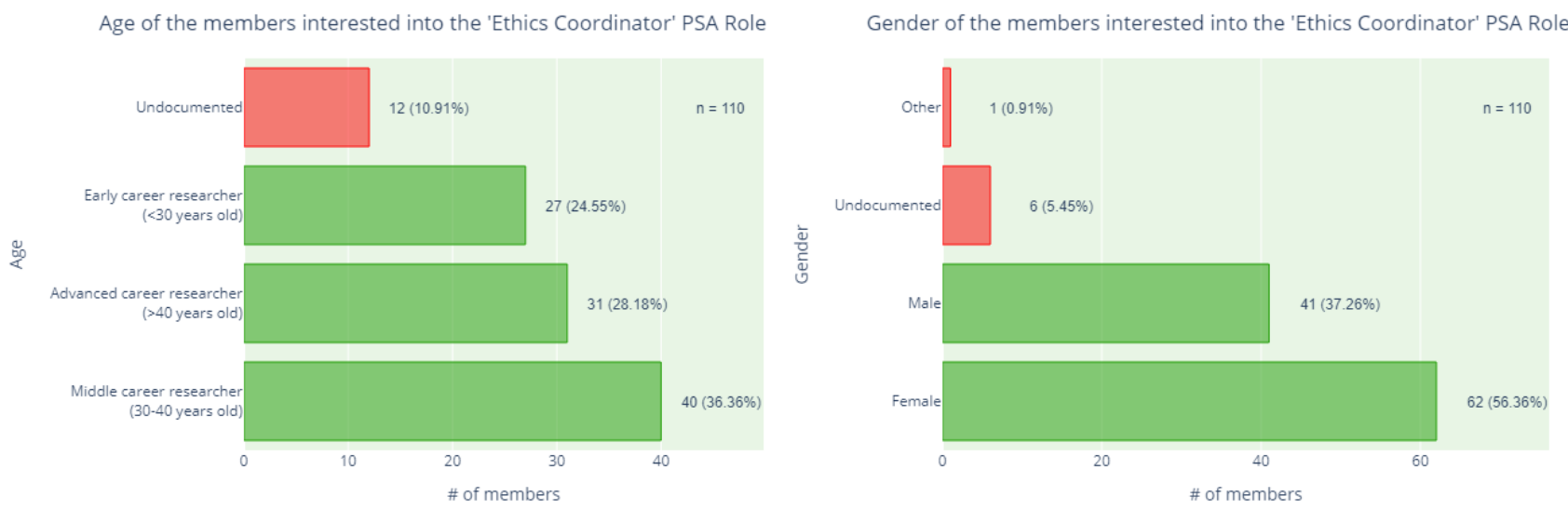

World region of the members interested into the 'Ethics Coordinator' PSA Role

Academic position of the members interested into the 'Ethics Coordinator' PSA Role
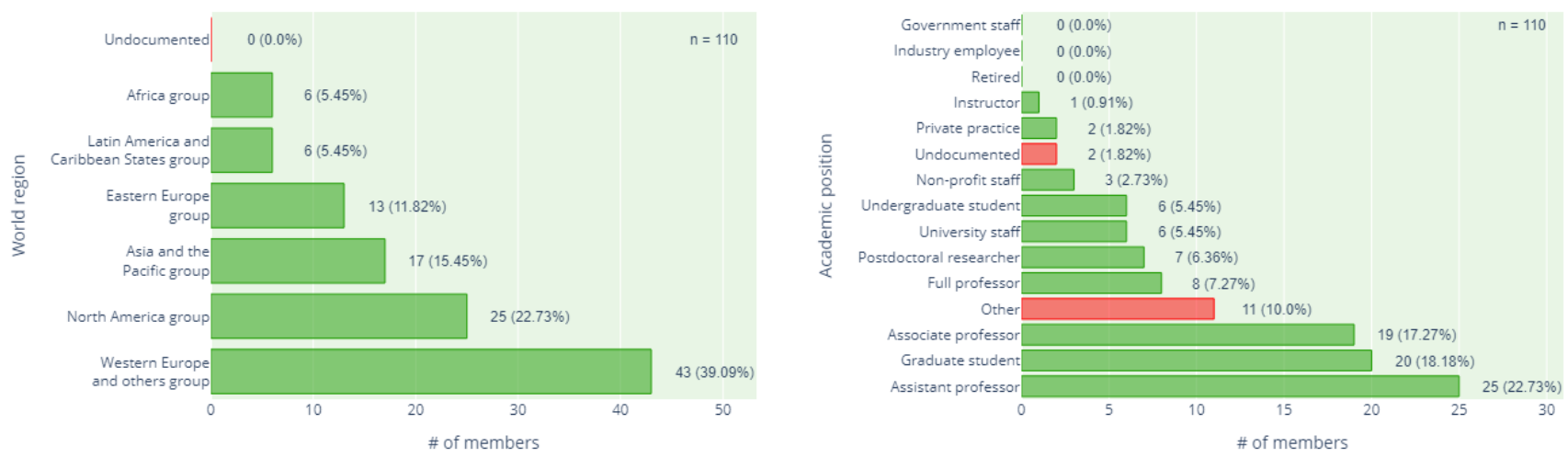

Macro speciality of the members interested into the 'Ethics Coordinator' PSA Role

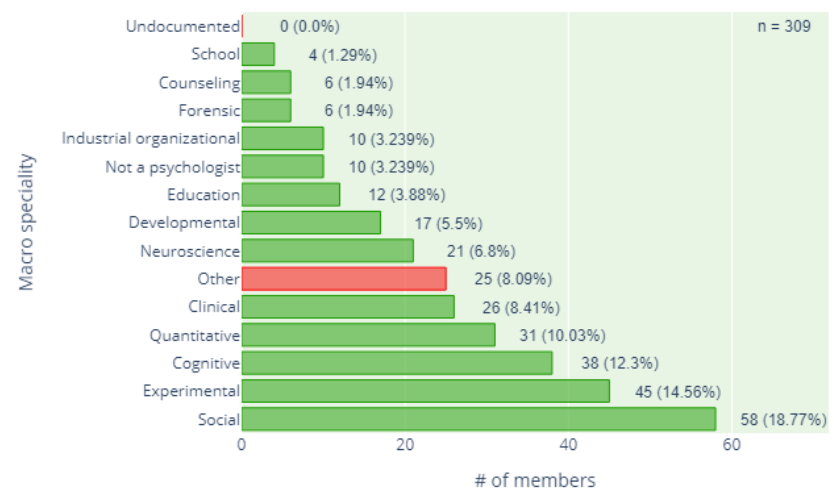




\section{c) Methodologist}

Figure 8. Number of members interested in the "Methodologist" role across age, gender, world region, academic position, and macro specialty.

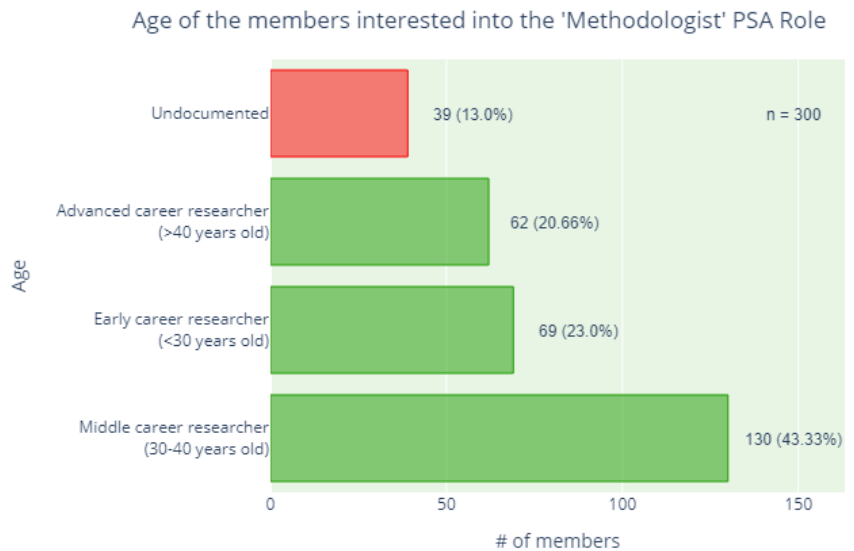

World region of the members interested into the 'Methodologist' PSA Role

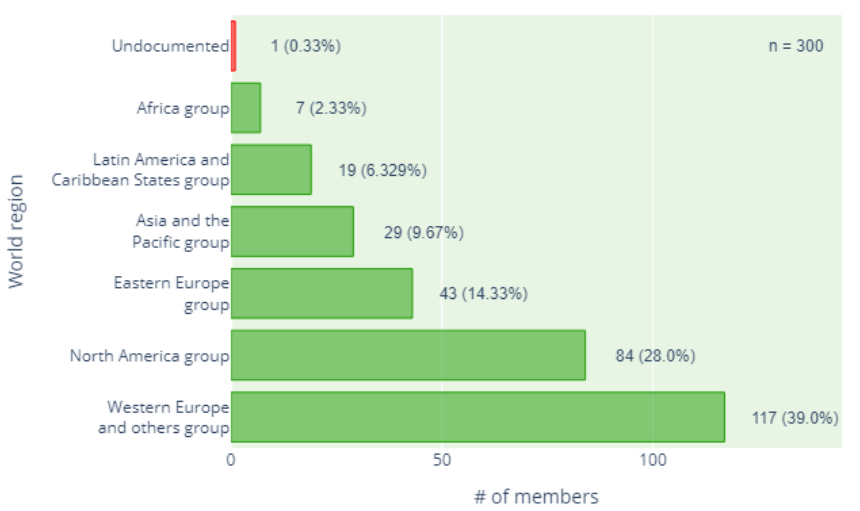

Gender of the members interested into the 'Methodologist' PSA Role

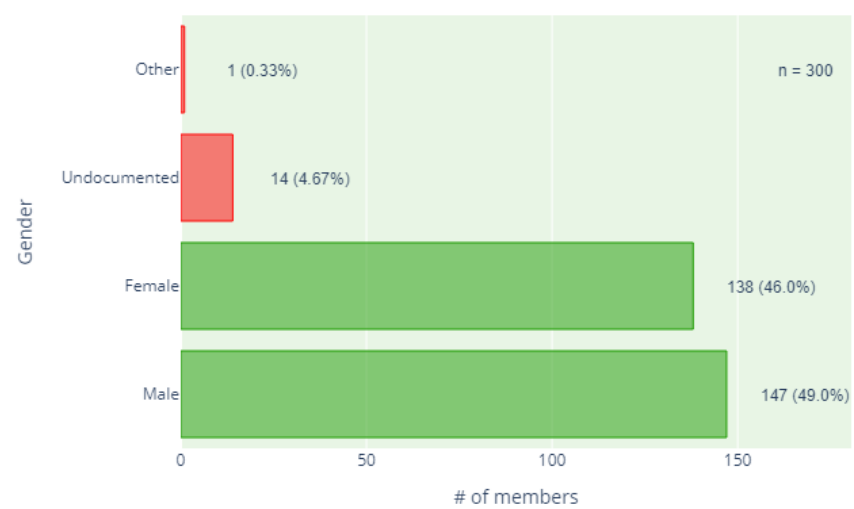

Academic position of the members interested into the 'Methodologist' PSA Role

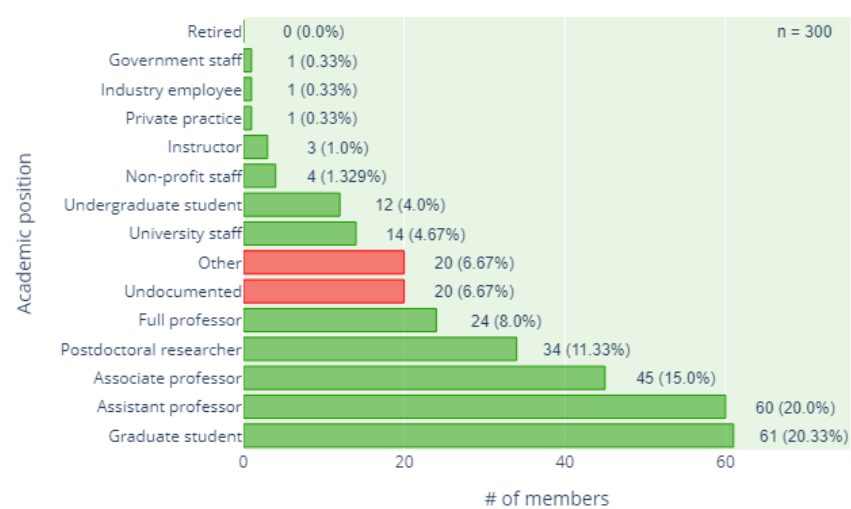

Macro speciality of the members interested into the 'Methodologist' PSA Role

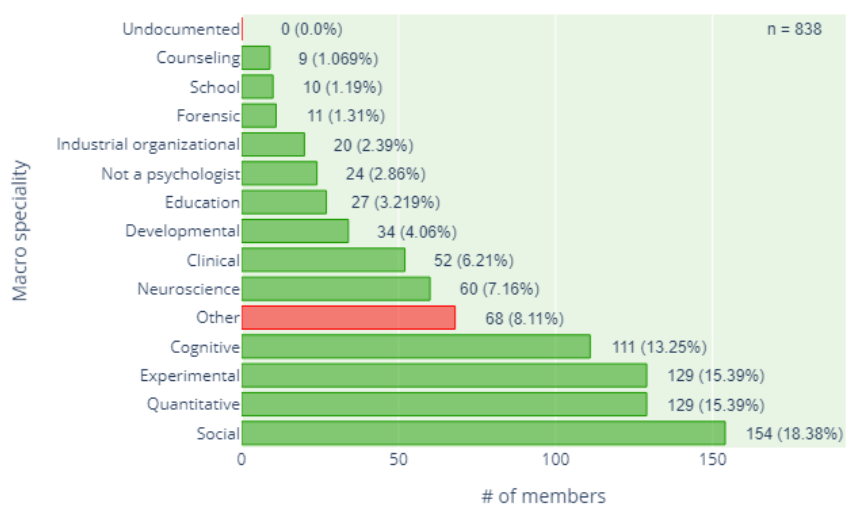




\section{d) Project monitor}

Figure 9. Number of members interested in the "Project Monitor" role across age, gender, world region, academic position, and macro specialty.
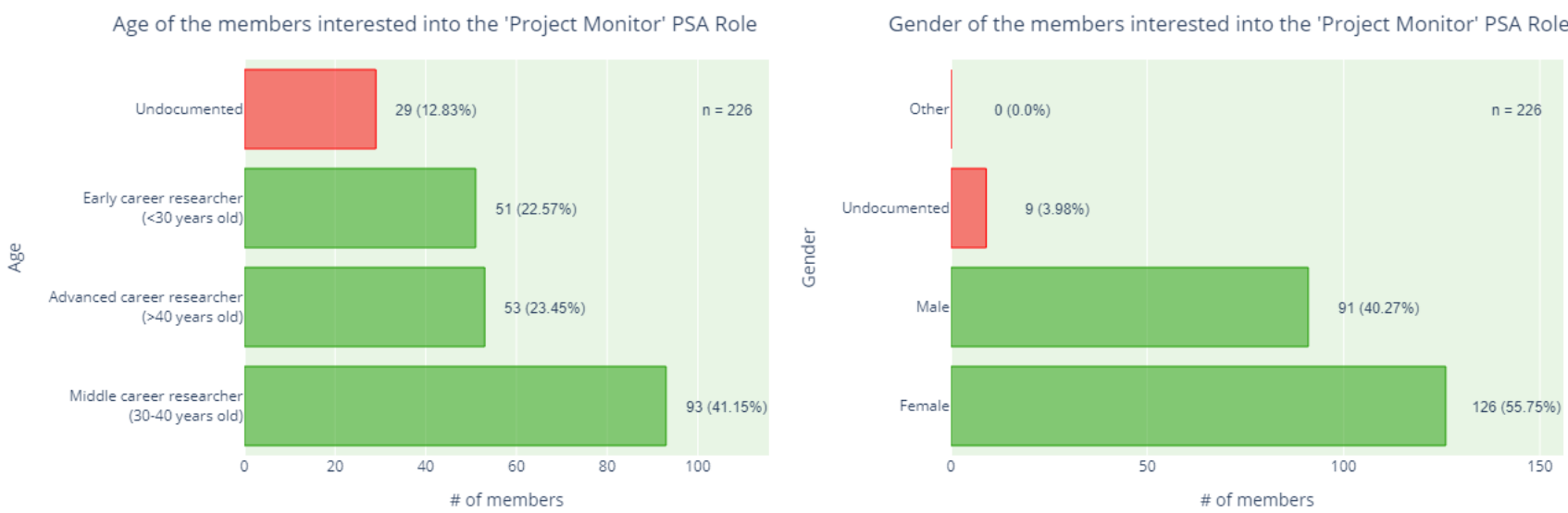

World region of the members interested into the 'Project Monitor' PSA Role

Academic position of the members interested into the 'Project Monitor' PSA Role
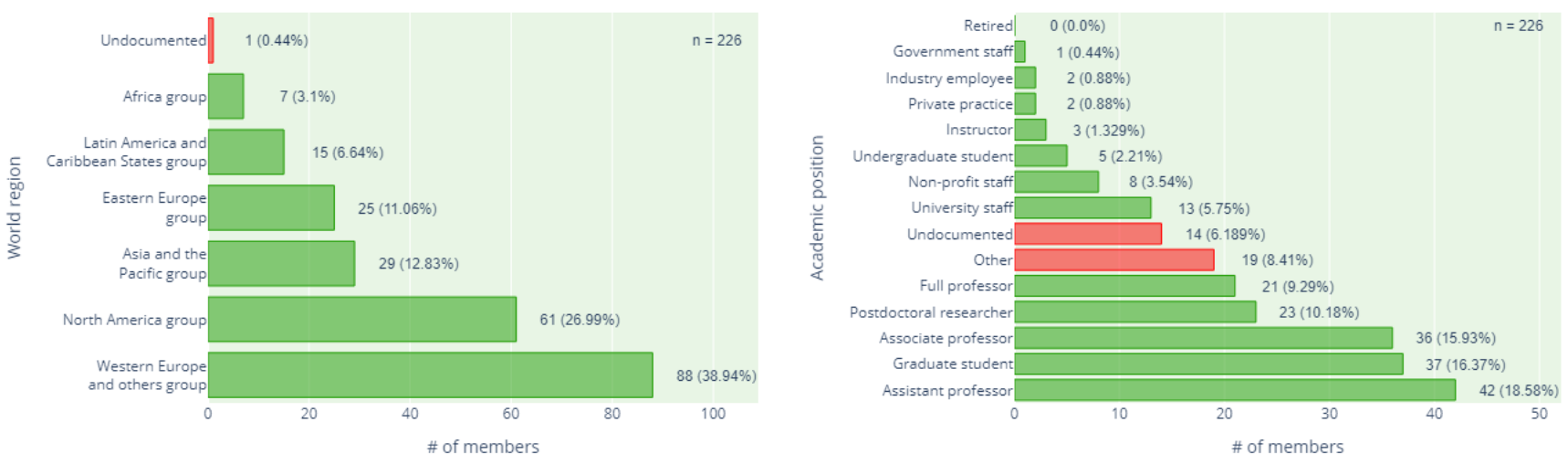

Macro speciality of the members interested into the 'Project Monitor' PSA Role

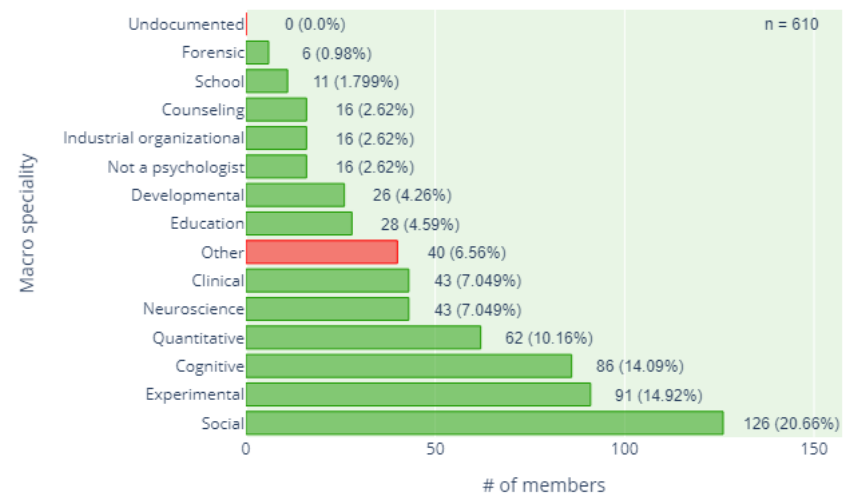




\section{e) Translation coordinator}

Figure 10. Number of members interested in the "Translation Coordinator" role across age, gender, world region, academic position, and macro specialty.
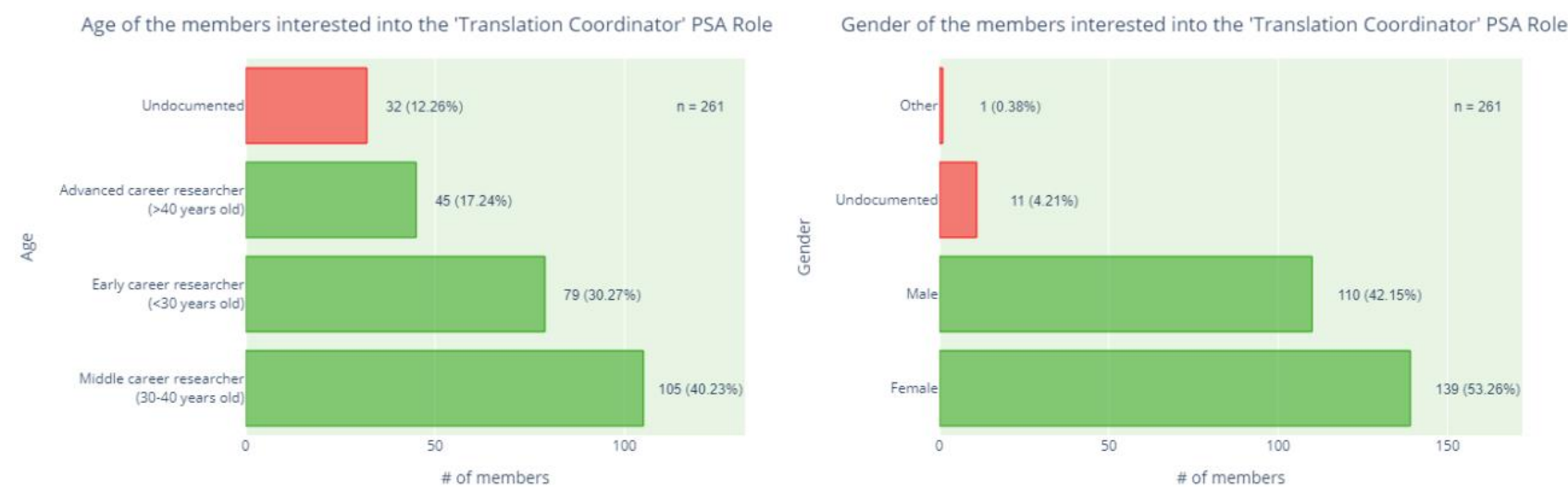

World region of the members interested into the 'Translation Coordinator' PSA Role Academic position of the members interested into the 'Translation Coordinator' PSA Role
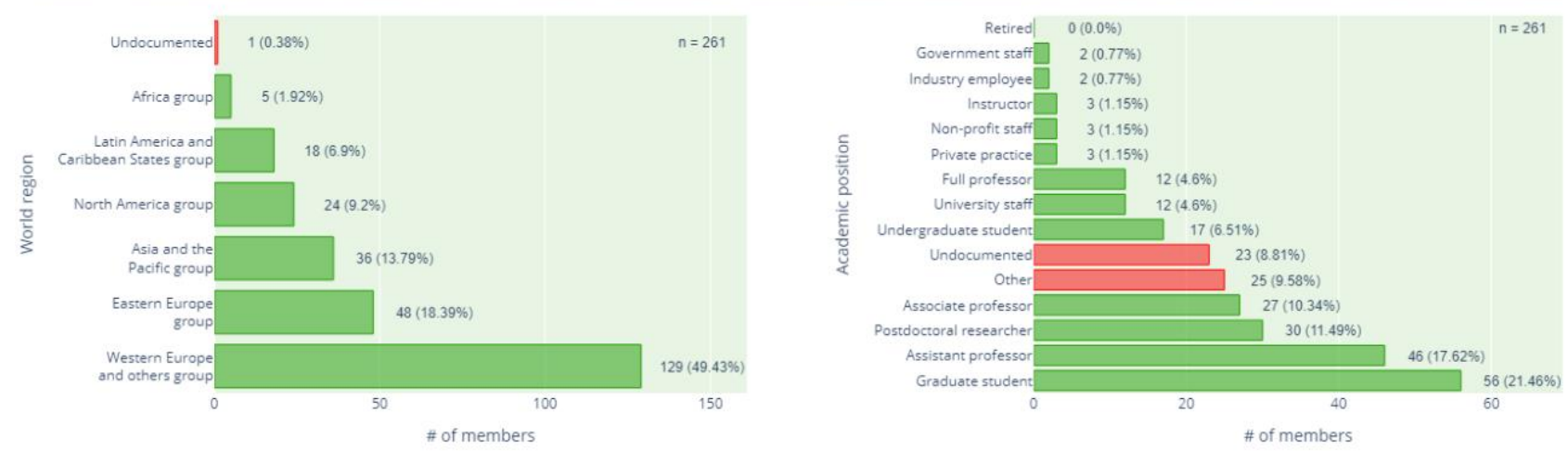

Macro speciality of the members interested into the 'Translation Coordinator' PSA Role

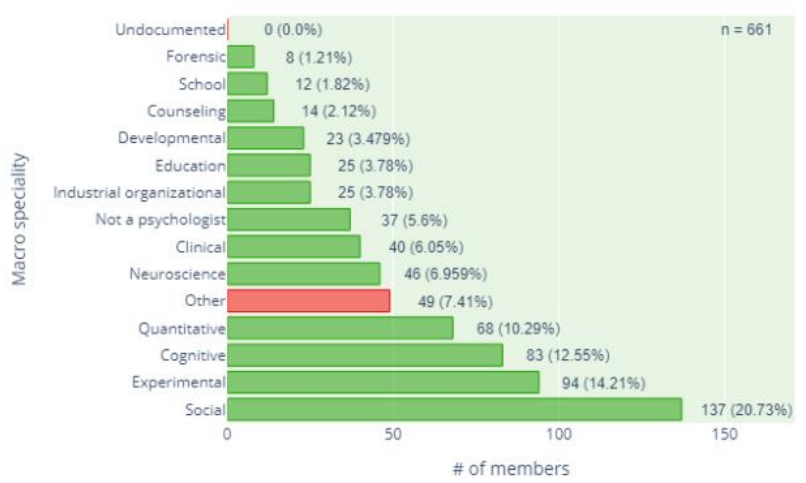

Technical notes (these apply for each PSA role)

- Specific answers

$\circ$ Undocumented means that the member didn't fill this profile field (none interpretable data).

O Other consists of a category of various categories that by themselves did not have a sufficient number to create its own category. 
- Categories

- World regions ${ }^{2}$ : We've created different clusters on the basis of the United Nations Regional Groups (see

https://en.wikipedia.org/wiki/United Nations Regional Groups). We deviated slightly from the distinction by creating an additional cluster for Canada and the USA (North America group)

- Age: We've arbitrarily created three different clusters ( $<30$ years old, 30-40 years old, $>40$ years old) which we named "early career researcher", "middle career researcher", and "advanced career researcher"

- Academic position: Here, we report all the different positions one can tick in the profile section.

- Macro specialty: Here, we report all the different research areas one can tick in the profile section

${ }^{2}$ For the "Western Europe and others group", "others" includes Australia, Israel, New Zealand, and Turkey. 


\section{Matched / Unmatched Requirements (+ Suggestions)}

This section highlights whether or not the different reporting requirements laid out in the PSA's Study Capacity Policy have been met. We also provide suggestions about how to better fulfill each requirement.

\section{1) Data Collection Capacity}

\begin{tabular}{|c|c|c|}
\hline Requirement & Matched/Unmatched & Suggestions \\
\hline $\begin{array}{l}\text { The report should describe the total } \\
\text { general data collection capacity for the } \\
\text { upcoming PSA reporting year. }\end{array}$ & Matched. & $\begin{array}{l}\text { Prior to the creation of these reports, we could } \\
\text { survey our members by asking them to estimate } \\
\text { a number of participants they could enroll in } \\
\text { PSA general studies for the upcoming year. That } \\
\text { could provide a more precise estimation of our } \\
\text { capacity than the current strategy (nothing } \\
\text { prevents us from using both strategies). When } \\
\text { doing so, surveyed members should report their } \\
\text { PSA ID to help match requirement } 3 \text { in a more } \\
\text { precise way. For a draft of what this survey } \\
\text { could look like, see Poll our members to retrieve } \\
\text { more accurate data }\end{array}$ \\
\hline $\begin{array}{l}\text { The report should describe PSA member } \\
\text { characteristics that could influence } \\
\text { specialized data collection capacity for } \\
\text { the upcoming PSA reporting year. }\end{array}$ & $\begin{array}{l}\text { Unmatched. As of } \\
\text { now, we don't have } \\
\text { enough information } \\
\text { about our members } \\
\text { to match this } \\
\text { requirement. }\end{array}$ & $\begin{array}{l}\text { A way we can estimate specialized data } \\
\text { collection capacity is through the addition of } \\
\text { new profile fields (e.g., Ability to compensate } \\
\text { participants with money? [Y/N]; Access to } \\
\text { medical imaging equipment? [Y/N]; Access to } \\
\text { specific software? [Y/N]; Access to a rare } \\
\text { population? [Y/N]). } \\
\text { What we can define as "special" is potentially } \\
\text { infinite. We must isolate some key } \\
\text { characteristics. For some guidelines on how we } \\
\text { could ask these information, see Regarding the } \\
\text { way we ask profile information }\end{array}$ \\
\hline $\begin{array}{l}\text { The report should provide some } \\
\text { breakdowns of how general and specific } \\
\text { data collection capacity varies across } \\
\text { important member characteristics. }\end{array}$ & $\begin{array}{l}\text { Matched (unmatched } \\
\text { for specific data } \\
\text { collection capacity). }\end{array}$ & $\begin{array}{l}\text { Beside the lack of information concerning } \\
\text { ethnicity (discussed in Regarding the way we } \\
\text { ask profile information), we feel that this } \\
\text { requirement is currently well matched. If you } \\
\text { think that we miss some information about our } \\
\text { members, we may consider adding new fields to } \\
\text { the profile section. }\end{array}$ \\
\hline
\end{tabular}


2) Administrative Capacity

\begin{tabular}{|c|c|c|}
\hline Requirement & Matched/Unmatched & Suggestions \\
\hline $\begin{array}{l}\text { The report should describe the } \\
\text { number of administrative hours } \\
\text { available for the upcoming PSA } \\
\text { reporting year for each PSA role. }\end{array}$ & $\begin{array}{l}\text { Neither / Crude } \\
\text { estimate. }\end{array}$ & $\begin{array}{l}\text { Prior to the redaction of these reports, we could } \\
\text { survey our members by asking them to estimate } \\
\text { a number of administrative hours they'd be } \\
\text { willing to allocate to each of the PSA roles for } \\
\text { the upcoming year ("On a weekly basis, how } \\
\text { many hours would you be willing to allocate to } \\
\text { this role?"). That could provide a more precise } \\
\text { estimation of our capacity than the current } \\
\text { strategy. When doing so, surveyed members } \\
\text { should report their PSA ID to help match } \\
\text { requirement } 3 \text { in a more precise way. For a draft } \\
\text { of what this survey could look like, see Poll our } \\
\text { members to retrieve more accurate data. } \\
\text { The way we should store and make use of this } \\
\text { information for more official members (e.g., } \\
\text { paid members, committee members, or studies } \\
\text { personnel) is still unclear, as recruitment may } \\
\text { occur whenever within an academic year. It is } \\
\text { worth mentioning that when officially recruiting } \\
\text { someone, we could define the number of hours } \\
\text { that this person should allocate to administrative } \\
\text { work for the PSA and store this information } \\
\text { somewhere. }\end{array}$ \\
\hline $\begin{array}{l}\text { The report should describe the } \\
\text { compensation available to pay for } \\
\text { administrative hours. }\end{array}$ & Unmatched. & $\begin{array}{l}\text { The qualified administrative members should } \\
\text { estimate this number on a yearly basis (at least). } \\
\text { Along with the available funds, we could } \\
\text { mention potential sources of funding that may } \\
\text { serve this purpose. }\end{array}$ \\
\hline $\begin{array}{l}\text { The report should describe } \\
\text { breakdowns of the potential } \\
\text { administrative labor pool by important } \\
\text { member characteristics }\end{array}$ & Matched. & $\begin{array}{l}\text { It could be of interest to monitor the different } \\
\text { demographics of our administrative roster } \\
\text { (director, associate directors, committee } \\
\text { assistant directors, committee members, studies } \\
\text { personnel, proposing authors of accepted } \\
\text { projects). For advice on how to do so, see } \\
\text { Keeping track of data that concern our } \\
\text { administrative team. }\end{array}$ \\
\hline
\end{tabular}




\section{Broad suggestions / Comments}

This section includes detailed suggestions on:

- How we could better match the different reporting requirements

- How we could prepare the writing of the reports

- How we could make a use of the reports

\section{Regarding the way we ask profile information}

- As outlined in Estimation of our administrative capacity, our members' interest in different administrative PSA roles does not often translate into concrete administrative work. This may be partly explained by the fact that we do not explain well how we will use member replies to their interest for different PSA roles. A short description of the different roles and how we use their answers may help our members to better select. Below is an image of what the rephrased item could look like.

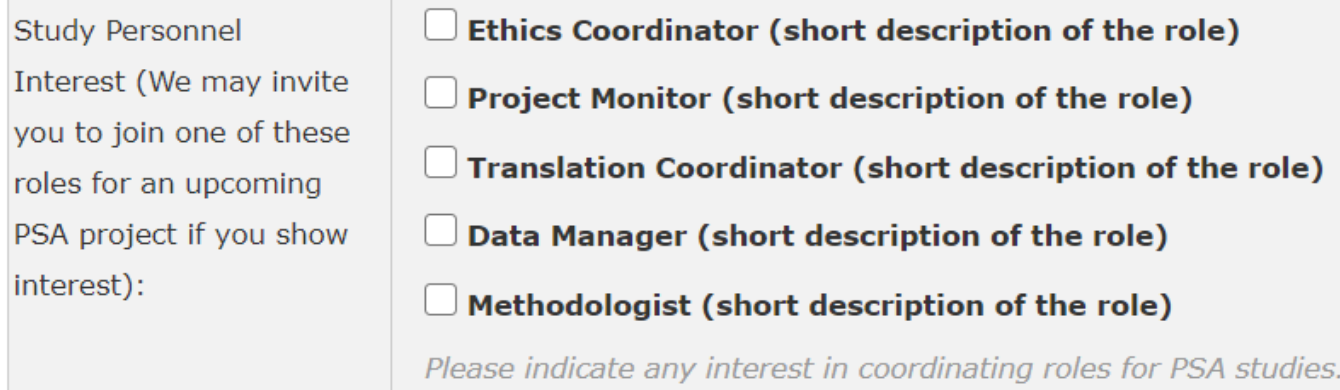

- To obtain more accurate answers (for all the profile fields), we suggest to warn our members before they access their profile page. We suggest the warning message to be "You are about to update your profile. The different pieces of information you will fill in will be in part used to (1) assess whether or not we respect our different core principles and in part used to (2) estimate our study capacity. The accuracy of the information you will provide is important for the functioning of the PSA. For instance, when searching for new leadership, we will use these pieces of information to target people to apply. We will also use these pieces of information to better understand whether we meet our inclusion criteria. We invite you to reflect very carefully before ticking boxes or filling fields."

- Profile information that comes from open-ended questions are harder to analyze. In comparison to closed questions, they require additional work (creation of clusters, coding of the answers). This problem may become even worse and time consuming as our list of members gets bigger. We suggest that we stick to a closed questions format as much as possible when adding new questions to the profile section.

- We also suggest that we make mandatory (as is the case for "area of specialty", for instance) the filling of the different profile fields we are interested in for the writing of these reports (this may not be legally possible for some profile fields, like ethnicity).

- Ethnicity: Ethnicity is quite difficult to code due to its open-ended format. It may not be possible to create ethnic categories that make sense across all world regions. If that is the case, it may also not make sense to provide big-picture breakdowns of ethnicity across the extremely nationally heterogeneous PSA membership 
- Study Personnel Interest: We may want to add the possibility to answer "none", so that non-interested members and members who didn't fill their profile ("undocumented") are not confounded.

\section{Defining inclusion and diversity criteria, and assessing whether they are fulfilled}

Currently, these reports only provide an estimation of our capacity to fulfill our inclusion and diversity principles over the upcoming year, whether it is for data collection or administrative work.

However, the PSA did not clearly define what the fulfillment of these principles means (e.g., from which percentage of researchers coming from non-WEIRD countries in our studies can we say that our diversity criterion is met? From which percentage of early-career researchers in our studies can we say that our inclusion criterion is met?)

We suggest that a part of the next versions of these reports can be dedicated to:

- The formulation of an inclusion and diversity goal to achieve for the upcoming year.

- The assessment of whether our previous inclusion and diversity goal was achieved or not. As we store the PSA profile IDs of those who participated in a PSA project, it would be easy, for instance, to check whether a certain percentage of early-career researchers participated in PSA projects during an academic year.

- Suggestions on how we could better fulfill this goal.

\section{Information that we should make easier to obtain}

We were able to retrieve most of the data we needed for the writing of these reports.

However, we missed some, and we think that some of those we retrieved could have been easier to reach. Here we state which information should be easy to reach and why. We also provide a template that the personnel of a PSA project could fill to ease the job of the one(s) who will write these reports. We argue that the use of templates for PSA projects won't only ease the redaction of these reports, but will also ease the monitoring of these projects through providing normalized tracking documents across projects.

- Information regarding the participating members of a PSA project (Sheet 1 of the template)

Each PSA project should at least store the PSA ID of the different participants of the project. That would allow us to track the profile (e.g., geographic region, gender, or age) of those who participate in our studies. Additional data that we could monitor could be CRediT roles undertaken by each member of the project or PSA personnel position taken (if any) by each member of the project.

- Information regarding the data collection process of a PSA project (Sheet 2 of the template)

Concerning the data collected in a PSA project, people in charge of the writing of the reports should be able to know (1) when each data has been collected, and (2) if each data is usable 
for data analysis or not. The first information would allow us to determine how much data has been collected during the previous academic year, and the latter would allow us to determine how much data is left to collect.

\section{Poll our members to retrieve more accurate data}

In their current forms, our reports are based on rude/raw (e.g., count of usable data collected in the previous year as an estimate of our general data collection capacity) and perhaps outdated (e.g., profiles being not updated frequently) information. We also miss some information that could help us match the different requirements of each report (see the different requirements we currently don't match, in Matched/Unmatched Requirements ( +

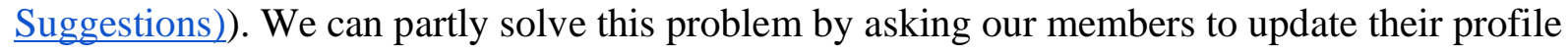
once a year and by polling them on, for instance, the estimated number of administrative hours they'd be willing to allocate to the different PSA roles. We provide a draft of what this poll could look like here.

This doesn't mean that we should drop the analyses we performed in the first reports over time. In fact, we could keep doing them and analyze the relation between these raw data and more subjective ones.

\section{Formalizing the writing process of these reports}

\section{- From a time perspective}

We suggest that the writing of these reports match the course of the academic year at the Director's institution. Ashland's academic year starts in September. As these reports aim at evaluating the administrative capacity and data collection capacity of the PSA once a year, it seems reasonable to us to have these reports ready in August.

\section{- Defining a roadmap}

Here we suggest a roadmap that we could follow to have both reports ready by the end of August.

(1) $15^{\text {th }}$ July to $15^{\text {th }}$ August: Poll our members + ask our members to update their profile (can be done as part of a PSA newsletter, but we may also want this process to be more formalized, and dedicate it a whole email).

(2) $15^{\text {th }}$ August to $31^{\text {st }}$ August:

a. Gather the different data (data from our members database, data from the survey's answers, and data from the different PSA Study tracker).

b. Perform the different analyses + writing of the reports.

\section{Keeping track of data that concern our administrative team}

Currently, no profile field allows us to filter for staff members (i.e., director, associate directors, committee assistant directors, committee members, studies personnel, proposing authors of accepted projects). That means that we cannot retrieve the different demographics 
of our administrative roster automatically and that we miss most of them (see Overview of our current administrative roster and World regions of our administrative roster).

To solve this issue, members could inform the administrative role(s) they occupy in the PSA (if any) in their profile section. A closed question format should suffice.

Alternatively, it could be of interest to retrieve demographics from the proposing authors of PSA projects. These could constitute data relevant to assessing our diversity and inclusion goals (e.g., ensuring that not all proposed projects come from WEIRD countries).

In order to do so, all of the proposing authors could submit their PSA profile ID as part of the different information required when submitting a PSA project. 


\section{Characteristics Choices}

This section details our choices concerning the member information we used or not for the writing of the reports

\section{Member information not reported}

We've decided not to report some information we could have retrieved (whether for the data capacity report or the administrative capacity report). We justify these choices below:

$\Rightarrow$ Reviewing Interest; Committee Interest; ORCID; OSF ID; Length of Time in Lab; Weekly Hours in Lab: not relevant for these reports.

$\Rightarrow$ Institution Affiliation; City of Residence; Native Language; Fluent Languages; Methodological Specialty: not relevant for these reports (and would constitute too complex data to analyze anyway, see Regarding the way we ask profile information).

$\Rightarrow$ Achieved Education Level; Lab Position: We felt that these dimensions would be redundant with / would give less information than the "Employment/Position" dimension.

$\Rightarrow$ Ethnicity: relevant to our reports, but would constitute too complex data to analyze in its current form (see Regarding the way we ask profile information).

\section{Member information reported}

We justify why we've chosen to report the different information present in this report:

$\Rightarrow$ Year of Birth; Gender Identity; Country Residence; Employment/position: is relevant for both reports:

- Allows to determine whether or not our diversity/inclusion goals can be fulfilled, whether for administrative or data collection purposes.

$\Rightarrow$ Study Personnel Interest: is relevant for the assessment of our administrative capacity.

$\Rightarrow$ Area Specialty: is relevant to both reports:

- Data collection capacity report: For instance, if we find that we don't have any neuroscience specialist in our network, we believe that it could influence study capacity decisions.

- Administrative capacity report: For instance, if we find that none of the social specialists of our network are interested in taking a "project monitor" role for our studies, we believe that it could influence study capacity decisions. 